\title{
Breeding and multiple waves of primary molt in common ground doves of coastal Sinaloa
}

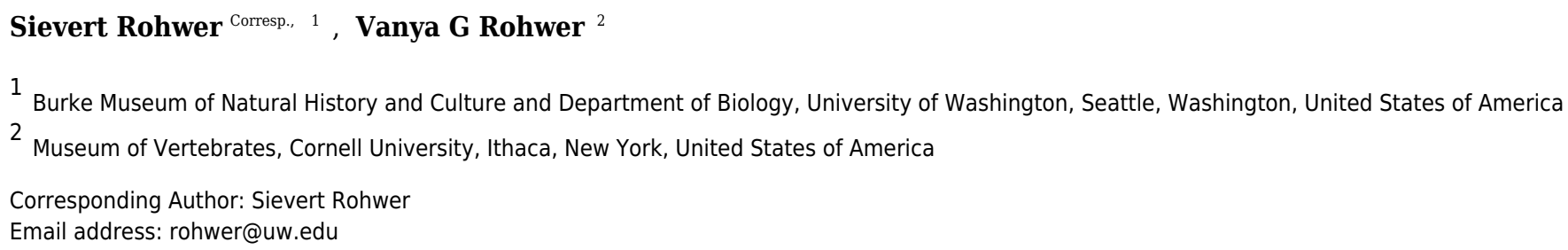

For adult Common Ground Doves from Sinaloa we demonstrate that the primaries are a single molt series, which sometimes feature two (in one case three) waves of feather replacement. Such stepwise primary replacement is found in many large birds but, at $40 \mathrm{~g}$, this dove is much the smallest species reported to have multiple waves of replacement proceeding through its primaries simultaneously. Pre-breeding juvenile Common Ground Doves never feature two waves of primary replacement. Juveniles usually have more than 2 adjacent feathers growing simultaneously and replace their primaries in about 100 days. In contrast adults, which extensively overlap molt and breeding, usually grow just a single primary at a time, and require at least 145 days to replace their primaries. Molt arrests are thought to drive the generation of new waves of primary replacement in a diversity of large birds. For adult Common Ground Doves, we found molt arrests to be strongly associated with active crop glands, suggesting that the demands of parental care cause arrests in primary replacement in this dove. For those adults with two primary molt waves, initiation of an inner wave was most frequently observed once the outer wave had reached P10. Thus, unlike reports for large birds, Common Ground Doves usually suppress the initiation of a new wave of molt starting at P1 when the preceding wave arrests before reaching the distal primaries. This assures that relatively fresh inner primaries are not replaced redundantly, overcoming a serious flaw in stepwise molting in large birds (Rohwer 1999). 
1 Breeding and multiple waves of primary molt in common ground doves of

2 coastal Sinaloa

3 Sievert Rohwer ${ }^{1}$ and Vanya G. Rohwer ${ }^{2}$

$4{ }^{1}$ Department of Biology and Burke Museum of Natural History and Culture, University of

5 Washington, Seattle, Washington, 98195, USA

$6{ }^{2}$ Cornell University Museum of Vertebrates, 159 Sapsucker Woods Road, Ithaca, New York, 7 14850, USA

8 Corresponding author:

9 Sievert Rohwer

10 Email address: rohwer@uw.edu 
11 Abstract: For adult Common Ground Doves from Sinaloa we demonstrate that the primaries are

12 a single molt series, which sometimes feature two (in one case three) waves of feather replacement. Such stepwise primary replacement is found in many large birds but, at $40 \mathrm{~g}$, this dove is much the smallest species reported to have multiple waves of replacement proceeding through its primaries simultaneously. Pre-breeding juvenile Common Ground Doves never feature two waves of primary replacement. Juveniles usually have more than 2 adjacent feathers growing simultaneously and replace their primaries in about 100 days. In contrast adults, which extensively overlap molt and breeding, usually grow just a single primary at a time, and require at least 145 days to replace their primaries. Molt arrests are thought to drive the generation of new waves of primary replacement in a diversity of large birds. For adult Common Ground Doves, we found molt arrests to be strongly associated with active crop glands, suggesting that the demands of parental care cause arrests in primary replacement in this dove. For those adults with two primary molt waves, initiation of an inner wave was most frequently observed once the outer wave had reached P10. Thus, unlike reports for large birds, Common Ground Doves usually suppress the initiation of a new wave of molt starting at P1 when the preceding wave arrests before reaching the distal primaries. This assures that relatively fresh inner primaries are not replaced redundantly, overcoming a serious flaw in stepwise molting in large birds (Rohwer 1999).

In large birds that fly while molting the primaries are often replaced in multiple waves that proceed simultaneously through these longest feathers of the wing. Two mechanisms can generate these waves. In several orders of large birds, the primaries constitute a single molt series, but multiple waves of primary replacement are generated by molt arrests. Following arrests, molt is re-initiated at the next feather to be replaced in molt waves that have not reached the distal-most primary and also at P1, the first feather of the primary molt series in most birds. Thus, depending on the history of arrests and molt progression, large species that fly while molting may have from one to four waves of replacement proceeding simultaneously through the primaries (Rohwer 1999). This is known as stafflemauser, or stepwise molt 
41 1984, Pyle 2005), and New World vultures (Snyder et al. 1987), among other groups. Multiple

42 waves of primary replacement are also achieved by dividing the primaries into two or more molt

43 series. Multiple replacement series differ from stepwise molt in that they start and, with

44 complete replacement, also stop, at predictable feathers within the wing. For large birds

45 multiple molt series in the primaries has been well documented in albatrosses (Langston and

46 Rohwer 1995, Rohwer et al. 2011) and in Falconiforms and Psittaciformes (Pyle 2013); multiple

47 molt series are also found in some kingfishers (Douthwaite 1971, Hamner 1980), cuckoos

48 (Rohwer and Broms 2013), and a bell bird (Marini and Silveira 2012).

49 At least in large birds, multiple waves of feather replacement in the primaries seem to facilitate more frequent replacement of the primaries because primaries may be growing at several loci that are separated by fully grown feathers. Some adaptation to increase the number of feathers grown simultaneously without creating large molt gaps in the wing is intuitively sensible because the time required to replace the primaries increases exponentially with body size and many birds over $1 \mathrm{~kg}$ do not replace all their primaries annually (Rohwer et al. 2009). In small birds for which the rules of primary replacement have been established, the primaries usually constitute as a single replacement series that are replaced in a single wave in a single bout of molting, without arrests. However, at least some small doves (Pyle et al. 2016; personal observation) and the Mustached Tree Swift (Hemiprocne mystacea) exhibit stepwise primary replacement (Rohwer and Wang 2010). Stepwise primary replacement is surprising in these species because they seem small enough to be able to complete primary replacement in a single bout of molting (Rohwer et al. 2008). What seems special about them is their extensive overlap in molt and breeding (Rohwer and Wang 2010).

While arrests and the re-initiation of molt are documented to drive the generation of multiple waves of primary replacement in large birds (Rohwer 1999), they are only suggested for small species. In Mustached Tree Swifts of the New Guinea region, which breed and molt year-round, primary replacement is stepwise, and the generation of multiple molt waves have been suggested to be associated with arrests caused by the demands of feeding young; however, evidence for this interpretation is lacking (Rohwer and Wang 2010). Nonetheless, arrests associated with demanding periods of parental care could prove to be a general mechanism for 
70 generating multiple waves of primary replacement in small birds that show extensive overlap in

71 molt and breeding. In contrast, reorganizing the primaries into multiple molt series would seem

72 to be a more improbable evolutionary transition than the development of stepwise molting, so

73 multiple series in the primaries may not characterize many groups of small birds.

74 We recently observed multiple waves of primary replacement in Common Ground Doves

75 (Columbina passerina) from northwest Mexico. Here we quantitatively summarize their primary

76 replacement to address two questions: 1) Do Common Ground Doves have stepwise primary

77 molt or have they broken the primaries into multiple series? and 2) Is breeding activity

78 associated with arrests in primary molt, thus making arrests a possible mechanism for

79 generating multiple waves of feather replacement in this small dove?

80 Distinguishing between stepwise primary replacement and having the primaries divided into

81 multiple molt series can be non-intuitive from "snap-shot" data gathered from many individuals

82 across the molting period (Rohwer 2008). Yet, the distinction is essential for understanding

83 evolutionary transitions in primary replacement strategies across birds. The key is to understand

84 that stepwise replacement is characterized by incomplete primary molts of unpredictable

85 extent, with the result that, in the next episode of molting where molt reinitiates in the

86 primaries distal to P1 varies across individuals. In contrast, the evolution of multiple molt series

87 in the primaries seems designed to generate complete primary replacement by dividing the

88 primaries into two or more short blocks of feathers, each of which is fully replaced in the same

89 short period of time during a single bout of molting (Rohwer and Broms 2011).

90 If Common Ground Doves have stepwise primary replacement, then three predictions should

91 refute the hypothesis that the primaries are organized into multiple molt series. First, in

92 stepwise molters, primary replacement should often be incomplete in a single bout of molting

93 but rarely or never so in species with multiple molt series in the primaries. Second, in stepwise

94 molters, juveniles undergoing their first bout of primary molt should possess only a single wave

95 of feather replacement beginning at P1 while in species with multiple molt series in the

96 primaries, juveniles molting for the first time should, like adults, initiate primary replacement at

97 two or more fixed loci. Third, in adults of species that are stepwise molters, P1 will dominate as 
98 a site of molt initiation, but other sites of initiation will be scattered throughout the primaries,

99 marking places where molt was reinitiated following an arrest. In contrast, when the primaries

100 are organized into multiple series, molt will be initiated at a few consistent sites in the primaries,

101 all with about equal frequency in composite summaries of "snap-shot" data (Rohwer and Broms

102 2011).

103 We use data from 180 common ground doves from coastal Sinaloa, Mexico to describe their

104 primary replacement rules. We document strong differences in the intensity of molt between

105 juveniles and adults, show that molt can be stepwise in breeding adults, and provide the first

106 evidence that arrests associated with parental care may be responsible for the generation of

107 multiple waves of primary replacement in a small bird. Common Ground Doves, like other

108 Columbiformes, regurgitate "crop milk", a liquid food consisting of protein, water and fat to their

109 young, and the production of crop milk allowed us to assess how feeding young is associated

110 with molt in breeding adults. Our results clearly show that this small dove overlaps molt and

111 breeding more or less completely, can replace its primaries completely during the breeding

112 season, and has evolved a mechanism to suppress the initiation of new waves of primary

113 replacement at P1 until the preceding wave has reached the distal primaries. This discovery

114 resolves an unexplained paradox in the Mustached Tree Swift (Rohwer and Wang 2010), which,

115 very likely, also has a mechanism for suppressing the immediate generation of new molt waves

116 at $\mathrm{P} 1$ when the inner primaries are little worn.

\section{METHODS}

118 Common Ground Doves are largely resident birds, with a range extending from the southern

119 United States through Central America, across northern South America, and throughout the

120 West Indies (Bowman 2002). They are among the smallest doves, with a mass of about 40

121 grams (UWBM specimens from Sinaloa). Breeding in juveniles can occur when they are about 6

122 months old (Johnston 1962; Passmore 1984); we also confirmed breeding by three birds in

123 partial juvenile plumage that were likely less than 6 months old. They do not defend territories

124 and exhibit little aggression (Nicholson 1937). Because the bursa of Fabricus is resorbed under

125 the influence of sex steroids (Mase and Oishi 1991), and because sex steroids are associated

126 with aggressive behavior, the very limited aggression reported for Common Ground Doves may 
127 explain why they are slow to resorb the bursa and, thus, why both males and females in

128 breeding condition often retain glandular bursas.

129 We studied Common Ground Doves on various communes in the Rio Fuerte flood plain between

130 Los Mochis on the coast and El Fuerte near the foothills of the Sierra Madre Occidental in

131 Sinaloa, Mexico. Prior to the development of massive irrigation, this region of coastal northwest

132 Mexico was largely deciduous thorn scrub that leafed out in late summer with the arrival of the

133 monsoon rains, but lost its leaves in November after the monsoons had ceased by the end of

134 September. Even with massive conversion to irrigated agriculture (Rohwer et al. 2015), ground

135 doves nesting here are exposed to intense solar radiation while foraging and often while on their

136 nests; thus, their feathers are subject to rapid fading from sunlight, as well as wear from the

137 hard and thorny vegetation they use for nesting. This rapid fading and wear of new feathers

138 enabled us to recognize blocks of newer and older feathers that were undoubtedly less than a

139 year's difference in age.

140 Molt scoring and the analysis of the rules of primary replacement followed Rohwer (2008).

141 Growing primaries were given fractional scores representing, to the nearest tenth, their length

142 as fully-grown feathers. New feathers were scored as 1 and old feathers as 0, but it is important

143 to note that these age assignments are unlikely to be year classes in this data set; instead they

144 represent activation classes of molt separated by unknown time intervals that likely were on the

145 order of a few months. Where blocks of adjacent feathers represented different replacement

146 classes, they were distinguished as newer or older than adjacent blocks. Rarely, adjacent groups

147 of primaries were extremely worn and faded and assigned a score of ragged; these were likely

148 feathers approaching a year of use that had been retained through the non-breeding season.

149 The total molt score for a bird was the sum of the values for its growing and new or newer

150 primaries. When molt scores from many individuals are summarized in tables, nodal feathers

151 mark loci in the primaries where molt is initiated, either with the commencement of the annual

152 molt or following arrests. In species with stepwise primary replacement and in species with the

153 primaries organized into multiple molt series, stable nodes predominate in summary tables

154 based on snap-shots of the molt status of many individuals; however, in stepwise molters,

155 transient nodes, which mark sites where molt was reinitiated following an arrest, will be 
156 recorded at lower frequencies at unpredictable sites distal to P1 where molt restarted after an 157 arrest.

158 We assessed breeding activity of doves that were captured and released by the presences or 159 absence of crop-milk; for doves that were prepared as specimens, we noted the condition of the 160 glands inside the crop, where vascularized crops with thickened walls indicated active milk 161 production. We also recorded dates for a number of nests with eggs or young.

162 We have restricted all of our analyses to observations we made in coastal Sinaloa from 2005 163 through 2011, during the months of May through September. Most of our field work in Sinaloa 164 was designed to study molt migrants (e. g. V. Rohwer et al. 2009, S. Rohwer et al. 2007, 2015, S. 165 Rohwer 2013); consequently, we have scored molt for only 15 birds for the months of May and 166 June, but many for the months of July through September. Some doves were collected and 167 many more were scored for primary replacement before being released when work on other 168 projects was slow. Time constraints, and not the condition of the bird, dictated whether birds were either collected or scored for molt and released; thus, our data should be an unbiased representation of the birds that we caught, even though our samples were obviously not collected systematically throughout the season. The number of birds scored for molt offers a good index of the relative amount of time we spent in the field in these months.

173 The approximately 40 ground doves that were collected were particularly important because 174 they had associated extended wings that were used to measure both primary length and 175 primary growth rates. Growth bands could not be seen in juvenile primaries; further, they were 176 faint and difficult to see in most primaries of most adults and could not have been measured on 177 specimens with folded wings. As part of our other studies of molt-migrants, we also collected or 178 scored for molt a smaller sample of Common Ground Doves in Arizona; however, these birds 179 were excluded from this study so possible geographic variation in the phenology of molting and 180 breeding of this resident bird would not confound our results. Our Arizona observations were 181 important, however, in demonstrating breeding by juveniles and multiple waves of primary 182 replacement in adults. 
183 Field work for this project was approved by the University of Washington Institutional Animal

184 Care and Use Committee (protocol 4309-01). Collecting for this project was conducted under 185 scientific collection permits issued by the Secretaría de Medio Ambiente y Recursos Naturales 186 (SEMARNAT) to the Facultad de Ciencias (B. Hernández-Baños FAUT 0169) of UNAM.

Primary replacement rules for juveniles.

Most of the 44 juveniles that we captured and scored for molt were replacing primaries, suggesting that they likely begin this molt shortly after fledging (Table 1). Of the 44 juveniles we scored, just one had not yet commenced flight feather replacement and retained all juvenile primaries and secondaries, and one other had either arrested molt at P4, or was replacing primaries so slowly that active molt was scored as an arrest. Four juveniles were omitted from our count of 42 that were molting because they had two waves of molt; at least two of these were precocious breeders and the other two were uninterpretable. We spent little time in the field in May and June, so the low numbers of juveniles scored in these months does not imply the production of few young during that time.

Without exception, juveniles replaced their primaries distally, starting at P1 (Table 2). P1 was strongly nodal and no other primary in our sample of 42 molting juveniles received a score of nodal, suggesting that arrests in the replacement of the juvenile primaries did not occur during the months of our field work. However, some late-fledged juveniles may be unable to complete their first primary molt, and these birds could be adding to the numbers of adults recorded as having multiple waves of primary replacement if we captured them in their second year. Our sample includes many more juveniles replacing inner than outer primaries, but good samples of juvenile ground doves growing primaries were available for all primaries except P8 and P9 (Table 2). Having samples for these distal most feathers requires recognizing remnants of juvenile feathers in other parts of the body, which we likely failed to do in some cases; this means that our sample of adults likely contains some older juveniles that were not recognized as such in the replacement was underestimated. 


\section{Primary replacement rules for adults.}

212 Primary replacement in adult Common Ground Doves is considerably more complex than it is in

213 juveniles (Table 3). Of the 126 adults we scored for molt, 108 (86 percent) were replacing

214 primaries; 5 of the 18 remaining adults had adjacent blocks of newer and more worn primaries

215 in their wings, suggesting that they had arrested primary replacement. Just $17 \%$ of the adults

216 that were growing primaries had two separate waves of molt. However, multiple waves of

217 primary replacement are more common in adults than this figure suggests because some adults

218 with arrested molt had two groups of newer primaries that were separated by one to several

219 older primaries. These non-molting adults clearly had had two waves of primary replacement;

220 when they are added to those with two active waves of molt, at least $21 \%$ of adults can be

221 inferred to have been replacing their primaries in two waves.

222 Reviewers of this paper observed that the relatively limited numbers of adult Common Ground

223 Doves with multiple molt waves suggests that adults showing two active molt waves could be

224 late-fledged juveniles from the preceding year that were unable to complete replacement of

225 their juvenile primaries. If this were the case, adults with multiple waves should be more

226 frequent early than late in the breeding season, but there was no evidence of a seasonal decline

227 in the frequency of adults showing two active waves of primary replacement $\left(X^{2}=2.37 ; p=\right.$

228 0.498; Table 4, May and June poled).

229 As in juveniles, the direction of primary replacement is strongly distal in adults, with no cases of

230 proximal replacement between any of the interior primary pairs (Table 5). However, molt arrests

231 in adults complicate scoring of directionality. Thus, directionality scores between P1 and P2

232 were distal in 6 adults, but proximal in 4 . These 4 proximal scores are almost certainly scoring

233 artifacts caused by P1 being too short to be compared for wear and fading with its adjacent

234 inner primaries. Recall that feathers scored as new are relatively fresh, and thought to have

235 been grown in that season and, further, that most cases of adjacent newer and older primaries

236 probably do not represent year-class differences in feather age because molt arrests are

237 common (see below). Thus, if P1 was growing, but too short to compare with P2 in its color and

238 freshness, then, the inferred direction of replacement between P1 and P2 will be proximal when 
239 P2 is also scored as fresh. However, if we had been able to determine that P1 was newer than

240 P2, directionality between this feather pair would have been scored as distal. All four of the

241 anomalous directional scores between P1 and P2 were cases where P1 was a pin feather or a

242 short brush just emerging from its sheath; thus, none of these 4 cases legitimately imply

243 proximal replacement between P2 and P1 because the age of P1 could not be assessed by

244 feather color. Further, we saw no evidence of P1 and the outer series of secondaries being part

245 of a single molt series (unpublished data).

246 A similar problem arises with arrests at P9. When molt is reinitiated at P10 and the feather(s)

247 immediately proximal to it are scored as old, then, by definition, the inferred direction of

248 replacement between P9 and P10 is proximal, readily accounting for the 6 proximal

249 directionality scores between P9 and P10 as artifacts of arrests (Table 5). In contrast, the 14

250 distal directionality scores between P9 and P10 are unambiguous. Summarizing, all of the

251 proximal directionality scores between primary pairs P1/P2 and P9/P10 can be interpreted as

252 scoring artifacts of the frequent arrests that characterize primary replacement in adult Common

253 Ground Doves; directionality between interior primary pairs was exclusively distal.

254 Unlike the situation in large birds, scattering of nodal and terminal feathers from P6 to P9 does

255 not only reflect the generation of multiple waves, but also the locations of arrested molts (Table

256 5). Nodal feathers mark the beginning of waves of replacement in the outer primaries.

257 However, they can only be recognized as nodal when an arrest has been long enough that the

258 feathers replaced in the preceding bout of molt have accumulated noticeable wear or fading.

259 Then, the primary at which a molt wave is re-activated will be newer than its proximal neighbor

260 and thus be scored as nodal. That the recognition of nodes in the distal primaries requires

261 arrests of sufficient duration to recognize older feathers surely means that our data

262 underestimates the number of adults inferred to have arrested primary replacement. The same

263 scoring problem arises when a proximal wave of replacement extends into older feathers from a

264 previous arrest. In these cases the distal-most growing feather in the proximal wave of active

265 molt will be scored as terminal because both of its neighboring feathers will be older than it is.

266 To reiterate, the scattering of feathers scored as nodal or terminal in the distal primaries 
267 confirms, but likely under-represents the frequency of arrested waves of primary replacement in 268 ground doves from Sinaloa.

269 Data linking breeding attempts with arrests in primary molt in adults is shown in Table 6 where 270 we compare crop gland activity with primary replacement. Many adults that were replacing 271 primaries had active crop glands, so molt is not always arrested when young are being fed (Table 272 6). Nonetheless, arrested primary replacement was strongly associated with having an active 273 crop gland (2-tailed Fisher's exact $p=0.002$ ), suggesting that adults providing crop milk to young 274 may arrest their molt to conserve energy. In large birds with stepwise primary replacement, 275 these arrests are thought to generate multiple waves of primary molt. When primary 276 replacement reinitiates, it picks up where it left off in the distal primaries and also starts anew at 277 P1, thus generating two or more waves of primary replacement.

278 Common Ground Doves stand in striking contrast to this understanding of stepwise primary 279 replacement in large birds. As we show in Figure 1, most arrests do not result in the generation 280 of a new wave of primary replacement at P1 when molt is resumed. Instead, new waves of molt 281 are not initiated in the inner primaries until the prior replacement wave has reached P10, or 282 sometimes P9 (Figure 1).

283 To show this we have used three common patterns of primary scores. First are birds showing 284 blocks of new feathers in the inner primaries (the outermost of which may be growing), and old 285 feathers in the outer primaries, characteristic of a single wave of primary molt. For these cases, 286 the outermost new or growing primary was plotted, giving the blue line in Figure 1. This line 287 shows that new waves are seldom initiated until molt has reached distal primaries P9 and P10.

288 All lines in this figure start with P3 because primary replacement had to have progressed far 289 enough into the wing for a block of new inner primaries to be discernable. In contrast, multiple 290 waves are represented by blocks of new or growing feathers in the inner and outer primaries, 291 separated by a block of old feathers in the middle primaries; in this case we plotted the 292 outermost new or growing primary (Figure 1, black line). This black line clearly shows that 293 blocks of new inner primaries are rarely seen until molt in the distal block of new primaries has 294 reached P9 (just 3 cases) or P10 (19 cases). Together, the contrasts between the blue and black 
295 lines strongly suggest that inner waves are suppressed, even if there are arrests, until primary

296 replacement has reached the outermost primary. Finally, the orange line confirms this

297 conclusion because it represents cases where molt could be seen to have been arrested in the

298 inner primaries (a block of new feathers) and restarted (a block of newer middle primaries),

299 while the outer primaries were scored as old. In this case, we plot the location of the arrests,

300 which we scored as the break between the inner new and outer newer feathers, and not the

301 outer most growing primary. This line is important because, while surely underestimating the

302 frequency of arrests (because new and newer blocks of feathers were not always distinguished),

303 it clearly illustrates primary replacement can arrests and restart from P5 to P7 without a new

304 molt wave initiating at P1. The take-home message of Figure 1 is that arrests in primary

305 replacement do not initiate new waves of replacement at inner primaries unless molt has

306 proceeded to the distal-most primaries.

307 Molt breeding overlap and molt duration.

308 Our records suggest that primary molt and breeding overlap extensively in Common Ground

309 Doves in Sinaloa (Table 4). We found nests and birds with active crop glands from May through

310 September and more than $50 \%$ of adults examined were molting in all of these months except

311 May (Table 4). The long breeding season and the extensive overlap of molt and breeding in

312 adult ground doves suggests that there should be little relation between day of year and primary

313 molt score for adults. When all the data are plotted (Figure 2), there is a significantly positive

314 trend (slope $=8.06, \mathrm{p}<0.0001 ; \mathrm{r}^{2}=0.27$ ), with replacement of the primaries being closer to

315 completion in September, which is likely near the end of the breeding season. This does suggest

316 that molt is scheduled to replace all primaries during the breeding season. It is critical to note,

317 however, that the distribution of points strongly suggests that the data is largely a composite of

318 two lines that are almost flat, representing the months of July and September when many adults

319 were scored for molt. This is indeed the theoretical expectation when some birds are

320 completing molt as others are just beginning (Rohwer and Broms 2012, Rohwer 2013). Thus, the

321 presence of two "flat" regression lines in Figure 2 is evidence that, as in other species, where

322 molt is little synchronized among individuals in a population, neither regression nor maximum

323 likelihood estimates of molt duration are reliable. Almost "flat" lines in Pimm regression plots

324 suggest extremely rapid molts, something that ground doves do not do. Such "flat" regression 
325 lines likely characterize many species that show extensive overlap in molt and breeding, and

326 they also occur when some individuals have completed primary replacement before others have

327 started, as is true in Painted Buntings, Passerina ciris (Rohwer 2013).

328 Following Rohwer and Broms (2012), we estimated the time required to replace the 10 primaries

329 in adult Common Ground Doves from the summed length of the primaries, primary growth rate,

330 and the number of primaries growing simultaneously. Our measurements for primary lengths

331 and growth rates are summarized in Table 7. For birds in active molt, the mean number of

332 primaries growing was 1.62 for adults and 2.52 for juveniles (weighted averages computed from

333 data in Table 3). Assuming no interruptions in the molt, which of course is not true in adults, but

334 the rule for juveniles, the number of days (D) required to replace all the primaries is

$\mathrm{D}=\mathrm{L} /(\mathrm{G} \times \mathrm{N})$,

336

337

338

339

340

341

342

343

344

345

346

347

348

349

350

351

352

where $L$ is the summed length of the 10 primaries, $G$ is primary growth rate measured in $\mathrm{mm} / \mathrm{d}$, and $\mathrm{N}$ is the mean number of primaries growing simultaneously. Using this equation, adult males are estimated to require 149 days to replace their primaries, adult females 145 days, and juveniles 101 days. Because birds were breeding during the extent of our field work from May through September, we do not know how much time they have to spend in molt. Nonetheless, these figures suggest that adults could replace all their primaries in less than the 5 months when we know they are breeding, so most adults should be able to complete their molt while they breeding, even with arrests during intense periods of parental care. Juveniles take considerably less time to molt but, if foraging is difficult during the dry months of winter, late-fledged juveniles may not be able to replace all their primaries before their first breeding season.

We show that the primaries of Common Ground Doves constitute a single molt series and are replaced distally from $\mathrm{P} 1$ to $\mathrm{P} 10$. In contrast to juveniles, adults often had two active waves of primary replacement and they usually had just one feather growing per wave. Molt arrests are thought to be the mechanism by which multiple waves of primary replacement develop in large birds (Rohwer 1999). Although, we document that molt arrests in adult Common Ground Doves are strongly associated with active crop glands, indicative of adults feeding young, arrests in 
353 primary replacement seem not to result in a new wave of molt starting at P1 unless earlier bouts

354 of primary replacement have reached P9 or P10. Juveniles replace their primaries in a single

355 wave that starts at P1 and no juvenile had two waves of primary replacement, unless they were

356 breeding precociously, as rarely occurs in this species (Johnston 1962, Passmore 1984). Stepwise

357 primary replacement is common in large birds, but this represents only the second well

358 documented case of stepwise molting in a small bird, the other being the Mustached Tree Swift

359 (Rohwer and Wang 2010). At 40 grams, Common Ground Doves are the smallest species for

360 which stepwise molting has been documented.

361 Stepwise primary replacement seems adaptive in large birds because it facilitates the generation

362 of multiple waves of primary replacement in species with too little time to replace all their

363 primaries annually (Stresemann and Stresemann 1966, Rohwer et al. 2009) or between breeding

364 attempts in species that breed year-round (Ashmole 1968). The key feature of stepwise primary

365 replacement is that molt recommences where it was arrested and also at P1 (Rasmussen 1988,

366 Shugart and Rohwer 1996, Rohwer 1999). Recommencing at P1 generates considerable within-

367 species flexibility in primary replacement, both across individuals and populations. Where the

368 time available to replace primaries is limited, the generation of multiple waves eventually results

369 in more primaries being renewed in each bout of molting, while more time for primary molt

370 should generate fewer waves of replacement, resulting in fewer molt gaps in the airfoil.

371 The discovery of stepwise primary replacement in small species that likely could replace all their

372 primaries annually begs the question of whether stepwise primary replacement is adaptive in

373 small species. We suspect it is because we see no reason that arrests must always be followed

374 by the generation of a new molt wave starting at P1. Although this is a key feature of stepwise

375 molting in large birds, reinitiating molt at P1 seems not to occur in Common Ground Doves until

376 replacement of the primaries has progressed at least to P9 or P10. Further, at least in some

377 shorebirds, arrests are frequent, but molt picks up where it was arrested, without starting over

378 at P1 (Pienkowski et al. 1976, Summers et al. 1989, Remsiewick et al. 2009). These shorebirds

379 are also small species that usually can replace all their primaries during the nonbreeding season.

380 The tendency for Common Ground Doves to suppress replacing P1 following arrests unless the

381 preceding molt wave has progressed into the distal primaries further suggests adaptation to 
382 stepwise molting in this small bird. We note, however, that satisfactorily addressing the

383 adaptive significance of stepwise molting in small species will surely require far more

384 descriptions of molt in small to mid-sized species that are not closely related.

385 In large birds, stepwise molting often results in the inner primaries being replaced two or more

386 times before the distal-most juvenile primaries are replaced for the first time (see diagram in

387 Rohwer 1999). This seems remarkably maladaptive because the outer primaries wear

388 considerably more than inner primaries, yet are the last to be replaced in young birds. Prior to

389 this study, the only mechanism identified for overcoming this problem was "omissive" molts,

390 reported for shags and large herons (Rasmussen 1988; Schugart and Rohwer 1995). In omissive

391 molts either P8, P9 or P10 is lost out of sequence in some (but not all) juveniles, thus setting up

392 replacement of outer primaries before the first wave of molt replacing juvenile primaries has

393 progressed into the distal primaries. Omissive molts have remained perplexing because only

394 some individuals show such replacement, and because the primary that is replaced varies.

395 These conundrums may be resolved by the recent discovery that some birds have the ability to

396 preferentially replace broken primaries or rectrices (Ellis et al. 2016). If omissive molts are

397 generated by the preferential replacement of extremely worn primaries, then the fact that not

398 all juveniles show this pattern of replacement in their outer primaries and that the replaced

399 primary can be any of three different feathers is resolved: very worn outer primaries could be

400 replaced out of their normal sequence; further, if the replaced feather is not the terminal

401 primary, its replacement could also start a distal wave of primary molt.

402 Our results for Common Ground Doves have revealed another, previously unknown mechanism

403 for avoiding unneeded frequent replacement of the inner primaries in birds with stepwise

404 primary replacement. Somehow, ground doves largely suppress initiation of new replacement

405 waves at P1 until the distal wave has proceeded to P9 or P10. Because inner primaries wear

406 more slowly than distal primaries, this suppression of new waves starting at P1 largely eliminates

407 frequent replacement of the inner primaries, something that has not, to our knowledge, been

408 reported for large birds (Rohwer 1999). This difference in when and how inner replacement

409 waves are generated in Common Ground Doves compared to large birds, suggests that this

410 stepwise-like molt may be better thought of as "stepwise with suppression". Clearly, some other 
411 mechanism regulating the activation of molt waves frees doves from initiating inner

412 replacement waves with the re-initiation of arrested outer waves. Common Ground Doves were

413 serendipitously well suited for this discovery because the number of primaries between the

414 distal growing feather in birds with two molt waves is little affected by differences between

415 feather lengths and growth rates, which vary little across their primaries (Table 7). Thus, data

416 from individuals with two waves of molt could be used for this test, without differences in the

417 time it takes to grow different feathers strongly biasing results.

418 Delaying the development of new waves of feather replacement starting at P1 also explains the

419 surprisingly greater frequency of growing feathers in the outer than in the inner primaries (Table

420 4), which, initially, seemed anomalous to us. If new waves that follow too closely on the heels of

421 a previous wave are suppressed, then molt summary tables (which aggregate molt scores across

422 many individuals) should show more growing primaries in the distal primaries. This is partly

423 because outer primaries are longer and take more time to grow, but that likely has little effect in

424 Common Ground Doves because the longest primaries (P7 or P8) are only 12mm longer than P1

425 (Table 7). Instead, this higher frequency of growing feathers in the distal primaries probably

426 results from new waves of replacement being suppressed in the inner primaries following

427 arrests until molt in the outer primaries has reached at least P9 or P10.

428 This pattern of more active molt in the distal primaries was also discovered in Mustached Tree

429 Swifts, but was perplexing to Rohwer and Wang (2010). Now it seems likely that the

430 suppression of new waves starting at P1 until the next distal wave has progressed into the distal

431 primaries could be a general solution to the problem of excess replacement of inner primaries in

432 small birds with stepwise-like primary replacement. In Mustached Tree Swifts the outer

433 primaries are progressively much longer than the inner primaries, but the strong break in the

434 frequency of replacement occurred between P5 and P6, with P6-10 showing about twice as

435 many growing feathers as P1-5. Because this was a more or less dichotomous break in

436 frequencies, despite progressive length differences in the primaries, we suggest that Mustached

437 Tree Swifts may also suppress the commencement of new replacement waves at P1 until molt in

438 the outer wave has progressed at least to P6. Another species with data consistent with

439 "stepwise with suppression" molts are Wood Pigeons (Columba palumbus), where late-hatched 
440 first year birds, as well as adults that had two waves of replacement in their primaries, had 5-6

441 newly replaced feathers between waves (Boddy 1981), suggesting suppression of an inner wave

442 until the outer wave has reached the distal primaries. Studies of marked and recaptured birds

443 with known breeding histories will be essential to support our suggestions that arrests are

444 responsible for generating multiple waves of primary replacement, and that new waves are

445 suppressed when an arrest occurs before the initial molt wave has progressed to P6 or beyond.

446 More broadly, pigeons and doves exhibit remarkable flexibility in their molts. Mourning Doves

447 (Zenaida macroura) and White-wing Doves (Zenaida asiatica) replace their primaries distally

448 from P1 to P10, in a single series with apparently few arrests (Otis et al. 2008). By contrast, we

449 have seen multiple waves of replacement in small Ptilinopus doves collected in the Solomon

450 Islands, and Pyle et al. (2016) report two waves of feather replacement in two Ptilinopus

451 poryphyraceus from American Samoa, suggestive of stepwise molting. Stepwise molts,

452 presumably generated by arrests for breeding, are also reported from some Band-tailed Pigeons,

453 Patagioenas fasciata, (Silovsky et al. 1968) and Wood Pigeons (Boddy 1981). These observations

454 suggest flexibility in the scheduling of annual molts relative to breeding opportunities. When

455 breeding conditions are favorable, some individuals in active molt arrest and then resume their

456 molts at multiple feather loci, while other individuals simply continue their annual molts without

457 arrests. Stopping and starting molt likely increases the potential for creating asymmetries

458 between wings, but any costs of asymmetric molts appear outweighed by the benefits of

459 additional breeding attempts. Pigeons and doves, with their specialized crop glands for feeding

460 young, may be especially prone to arrested molts when the food demands of young are high.

461 Many of the regions in coastal Sinaloa where we worked have been converted to irrigated

462 agriculture (Rohwer et al. 2015), which provides extensive habitat and more predictable mesic

463 areas around fields that are excellent for breeding by Common Ground Doves. This also means

464 that breeding opportunities for ground doves may extend for longer periods of time and be less

465 confined to the annual late-summer monsoon (Comrie and Glenn 1998) than would have been

466 the case prior to the 1970s, when reservoirs and extensive systems of cement-lined canals began

467 to be developed in coastal west Mexico (Rohwer et al. 2015). The possibility that landscape-

468 level changes has affected the phenology of molt and breeding or the extent of molt-breeding 
469 overlap could be assessed by comparing ground doves in parts of Sonora where monsoon rains

470 continue to drive the annual vegetation cycle in the absence of irrigation.

471 As more tropical species are examined that exhibit extensive molt breeding overlap, many more

472 small species will likely be discovered to replace their primaries in multiple waves, either in a

473 stepwise fashion, or by dividing the primaries into multiple series. Distinguishing between these

474 two strategies requires data on substantial numbers of actively molting birds summarized in

475 tables similar to those presented here. As more such studies accumulate, the comparative

476 studies they will support should help illuminate both the evolutionary history and lability of

477 primary replacement patterns across birds and how primary replacement strategies are

478 integrated into other major life-history features of birds.

479

480

481

482

483

484

485

486

487

488

489

490

491

492

493

494

495

REFERENCES

Ashmole, N. P. 1968. Breeding and molt in the White Tern (Gygis alba) on Christmas Island, Pacific Ocean. Condor 70:33-55.

Bowman, Reed. 2002. Common Ground-Dove (Columbina passerina), The Birds of North America (P. G. Rodewald, Ed.). Ithaca: Cornell Lab of Ornithology; Retrieved from the Birds of North America: https://birdsna.org/Species-Account/bna/species/cogdov DOI: $10.2173 /$ bna.645.

Boddy, M. 1981. Primary moult in juvenile and adult woodpigeons. Ringing \& Migration 3:113122.

Comrie, A. C., and E. C. Glenn. 1998. Principal components based regionalization of precipitation regimes across the southwest United States and northern Mexico, with an application to monsoon precipitation variability. Climate Research 10:201-215.

Dorward, D. F. 1962. Comparative biology of the White Booby and the Brown Booby at Ascension. Ibis 103b: 174-220.

Douthwaite, R. J. 1971. Wing moult of the Pied Kingfisher Ceryle rudis (Linn.). Bulletin of the British Ornithologists' Club 91:147-149.

Edelstam, C. 1984. Patterns of moult in large birds of prey. Ann. Zool. Fennici 21:271-276. 
496 Ellis, D. H., V. G. Rohwer, and S Rohwer. 2016. Experimental evidence that a large raptor can

497 detect and replace heavily damaged flight feathers long before their scheduled moult dates. 498 Ibis 159:217-220.

499 Hamner, D. B. 1980. Mensural and moult data for eight species of kingfisher from Mozambique 500 and Malawi. Ostrich 51:129-150.

501 Johnston, R. F. 1962. Precocious sexual competence in the Ground Dove. Auk 79:269-270.

502 Passmore, M. F. 1984. Reproduction by juvenile Common Ground Doves in south Texas. Wilson $503 \quad$ Bulletin 96:241-248.

504 Langston, N. E., and S. Rohwer. 1995. Unusual patterns of incomplete primary molt in Layson 505 and Black-footed Albatrosses. Condor 97:1-19.

506 Mase, Y., and T. Oishi. 1991. Effects of castration and testosterone treatment on the 507 development and involution of the bursa of Fabricus and the thymus in the Japanese Quail. $508 \quad$ General and Comparative Endocrinology 84:426-433.

509 Nicholson, D. J. 1937. Notes on the breeding of the ground dove in Florida. Wilson Bulletin $510 \quad 49: 101-114$.

511 Otis, David L., John H. Schulz, David Miller, R. E. Mirarchi and T. S. Baskett. 2008. Mourning Dove 512 (Zenaida macroura), The Birds of North America (P. G. Rodewald, Ed.). Ithaca: Cornell Lab of 513 Ornithology; Retrieved from the Birds of North America: https://birdsna.org/Species-

$514 \quad$ Account/bna/species/moudov. DOI: 10.2173/bna.117

515 Pimm, S. 1976. Estimation of duration of bird molt. Condor 78:550-550.

516 Pyle, P. 2005. Remigial molt patterns in North American Falconiformes as related to age, sex, 517 breeding Status, and life-history strategies. Condon 107:823-834.

518 Pyle, P. 2013. Evolutionary implications of synapomorphic wing-molt sequences among falcons 519 (Falconiformes) and parrots (Psittaciformes). Condor 115:593-602.

520 Pyle, P., K. Tranquillo, K. Kayano, and N. Arcilla. 2016. Molt patterns, age criteria, and molt521 breeding dynamics in American Samoan landbirds. Wilson Journal of Ornithology 128:56-69.

522 Rasmussen, P. C. 1988. Stepwise molt of remiges in Blue-eyed and King Shags. Condor 94:297523300.

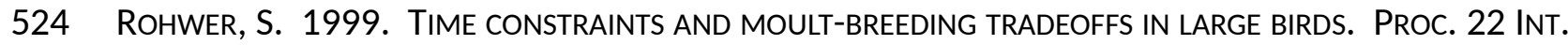
525 Ornithol. Congr., Durban: 568-581. JohanNeSBurg: BirdLife SOUTH Africa.

526 ROHWER, S. 2008. A primer on summarizing molt data for flight feathers. Condor 110:799-806. 
527 Rohwer, S. 2013. Molt intensity and conservation of a molt migrant (Passerina ciris) in

$528 \quad$ Northwestern Mexico. Condor 115:421-433.

529 Rohwer, S., and K. Broms. 2013. Replacement rules for the flight feathers of Yellow-billed

530 Cuckoos (Coccyzus americanus) and Common Cuckoos (Cuculus canorus). Auk 130:599-608.

531 Rohwer, S., and L.-K. Wang. 2010. A quantitative analysis of flight feather replacement in the

532 Moustached Tree Swift Hemiprocne mystacea, a tropical aerial forager. PLoS One 5:e11586.

533 Rohwer, S., E. Grason, and A. G. Navarro- Siguenza. 2015. Irrigation and avifaunal change in

534 coastal Northwest Mexico: has irrigated habit attracted threatened migratory species? PeerJ

535 3:e1187; DOI 10.7717/peerj.

536 Rohwer, S., A. G. Navarro, and G. Voelker. 2007. Rates versus counts: Fall molts of Lucy's

537 Warblers (Vermivora luciae). Auk 124:806-814.

538 Rohwer, S., A. Viggiano, and J. M. Marzluff. 2011. Reciprocal tradeoffs between molt and

539 breeding in albatrosses. Condor 113:61-70.

540 Rohwer, V. G., S. Rohwer, and M. F. Ortiz-Ramirez. 2009. Molt biology of resident and migrant

541 birds of the monsoon region of west Mexico. Ornitología Neotropical 20:565-584.

542 Shugart, G. W., and S. Rohwer. 1995. Serial descendant primary molt or Staffelmauser in Black-

543 crowned Nightherons. Condor 98:222-233.

544 Silovsky, G. D., H. W. Wight, L. H. Sisson, T. L. Fox, and S. W. Harris. 1968. Methods for

545 determining age of Band-tailed Pigeons. Journal of Wildlife Management 32:421-424.

546 Silveira, M. B., and M. A., Marini. 2012. Timing, duration and intensity of molt in birds from a

547 Neotropical savanna in Brazil. Condor 114:435-448.

548 Snyder, N. F. R., E. V. Johnson, and D. A. Clendenen. 1987. Primary molt of California Condors.

$549 \quad$ Condor 89:468-485.

550 Stresemann, E., and V. Stresemann. 1966. Die Mauser der Vogel. Journal fur Ornithologie 107:1-

$551 \quad 448$. 


\section{Figure 1 (on next page)}

The progression of molt in outer molt waves corresponds to the initiation of inner molt waves in adult Common Ground Doves.

Individuals with a single molt wave (blue line) are commonly observed until molt has progressed to P9 and P10. By contrast, the frequency of individuals with two molt waves (black line) dramatically increases once the outer molt wave has reached P10. Individuals that arrested and re-initiated molt without starting a new series at P1 (orange line) show that arrests do not activate a molt series at P1, as occurs in large birds. All lines start at P3 because our scoring scheme required groups of feathers for determining feather ages. See text for more information. 


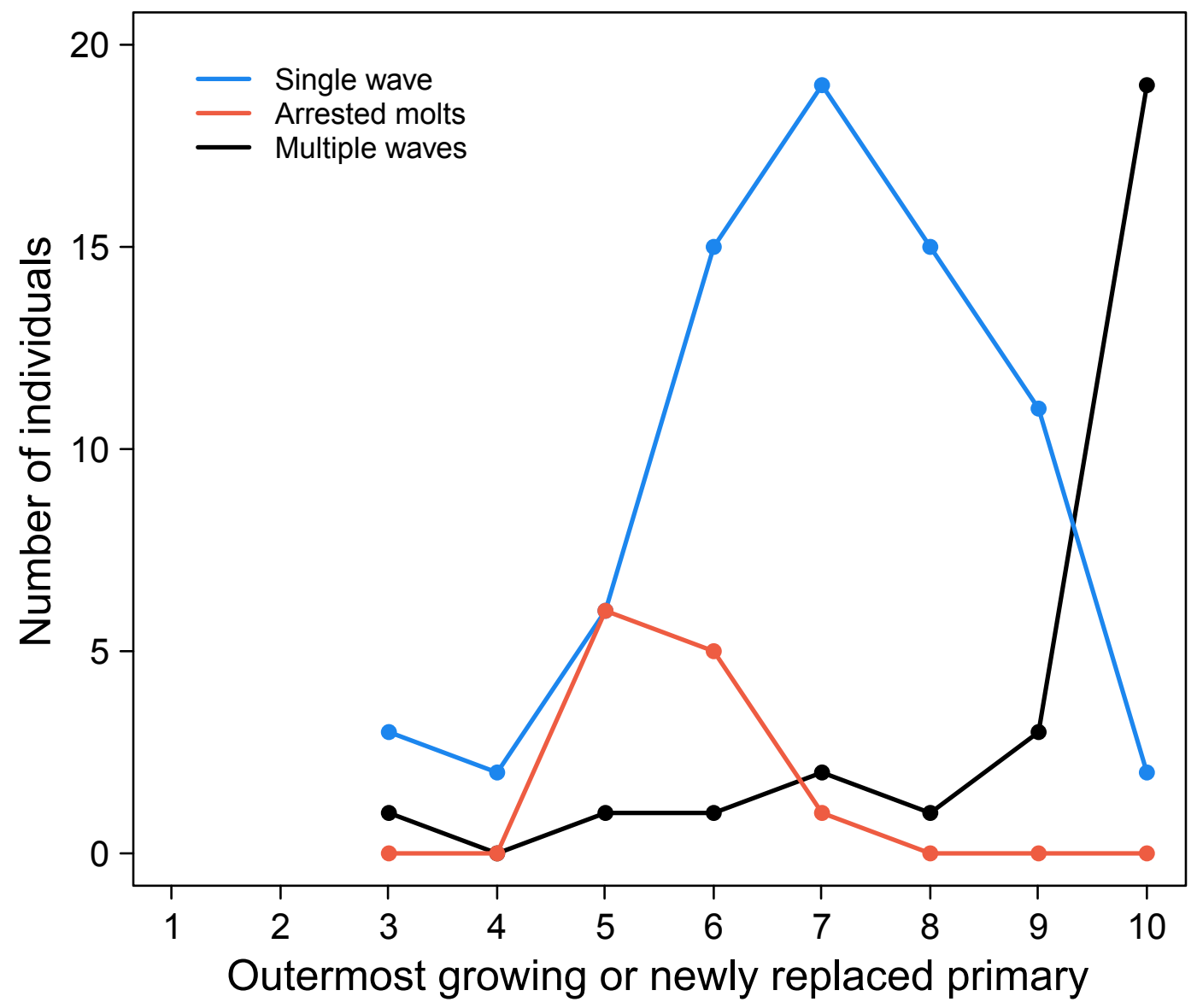


Figure 2 (on next page)

Progression of molt in adults.

Pimm (1976) regressions fail to correctly estimate the duration of primary replacement when start and finish dates overlap broadly in the studied population, as is the case for these doves. Thus of the progression of molt in adults largely reflects birds in various stages of molt in the months of July and September when most of our birds were scored. 


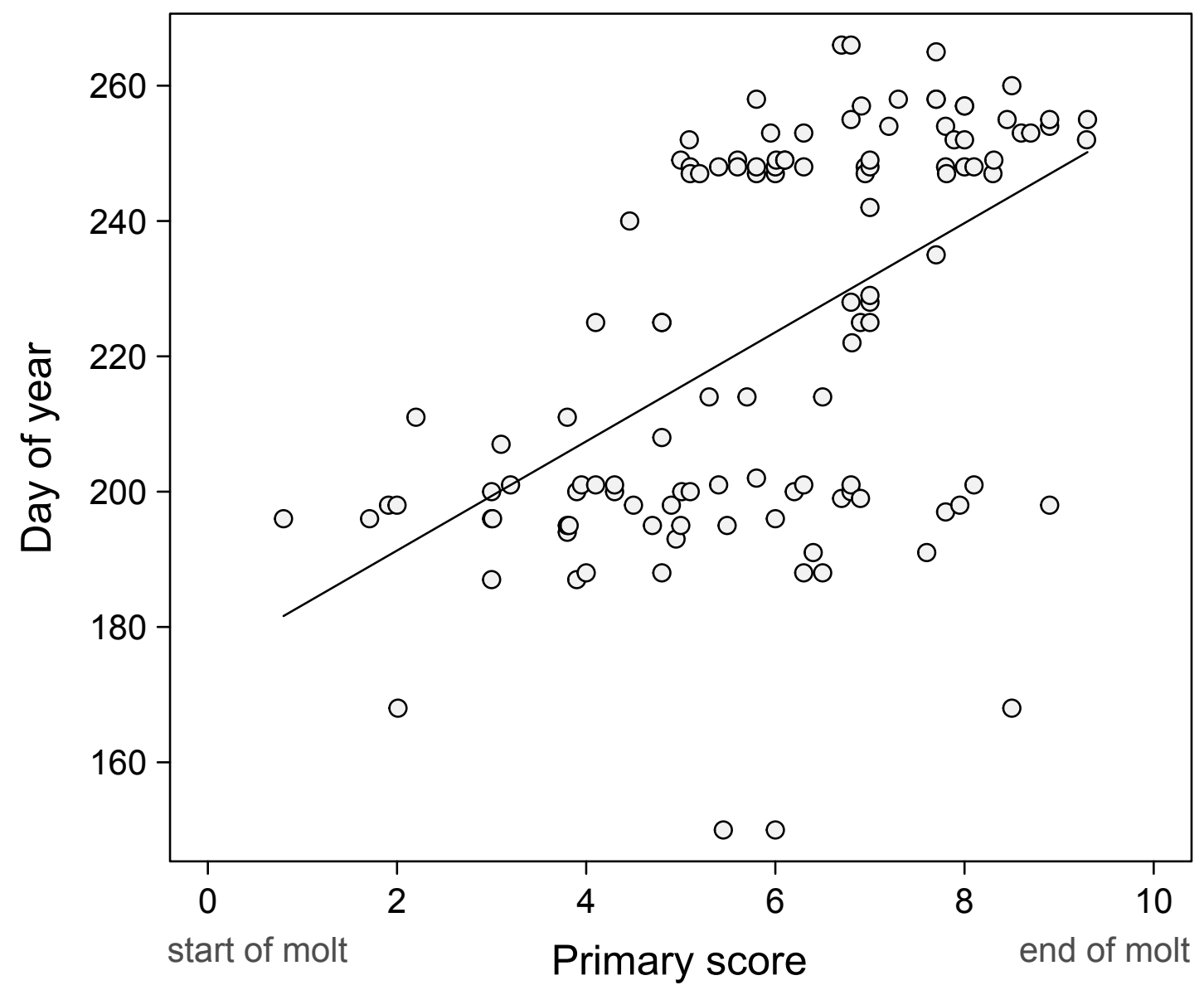




\section{Table 1 (on next page)}

Summary of primary molt in juvenile Common Ground Doves by month. 
Table 1. Summary of primary molt in juvenile Common Ground Doves by month.

\begin{tabular}{cccc} 
Month & $\begin{array}{c}\text { \# juvs } \\
\text { sampled }\end{array}$ & $\begin{array}{c}\text { \# replacing } \\
\text { Ps }\end{array}$ & $\begin{array}{c}\text { \% replacing } \\
\text { Ps }\end{array}$ \\
\hline May & 1 & 1 & 100 \\
Jun & 5 & 5 & 100 \\
Jul & 10 & 9 & 90 \\
Aug & 7 & 6 & 86 \\
Sep & 21 & 21 & 100 \\
\hline Totals & 44 & 42 & 95
\end{tabular}




\section{Table 2 (on next page)}

Summary table for 40 juvenile Common Ground Doves that were growing primaries.

Note that the primaries are a single molt series with $\mathrm{P} 1$ nodal and P10 terminal and directionality always distal. Excluded are 4 juveniles with multiple waves of primary replacement, possibly associated with late fledging or precocious breeding. 
Table 2. Summary table for 40 juvenile Common Ground Doves that were growing primaries.

Excluded are 2 juveniles with multiple waves of primary replacement, presumably associated with precocious breeding.

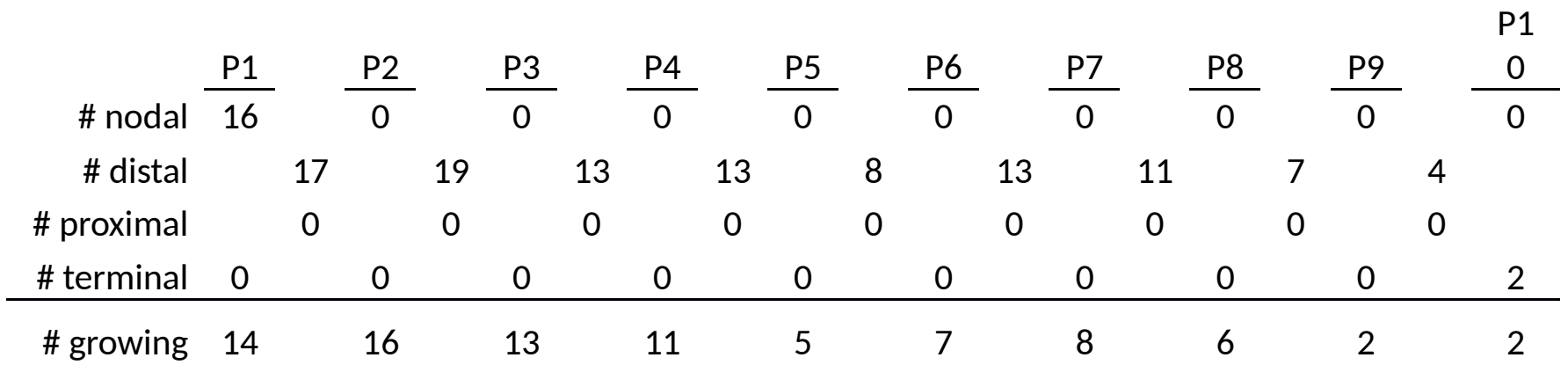




\section{Table 3 (on next page)}

Number of primaries growing for two classes of adults and for juveniles. 
Table 3. Number of primaries growing for two classes of adults and for juveniles.

\begin{tabular}{lcccc} 
& \multicolumn{5}{c}{ Number of growing primaries } \\
\cline { 2 - 5 } & 1 & 2 & 3 & 4 \\
\hline Adults, 1 wave & 102 & 15 & 1 & 0 \\
Adults, 2 waves & -- & 14 & 4 & 0 \\
Juveniles, 1 wave & 12 & 16 & 6 & 4
\end{tabular}




\section{Table 4(on next page)}

Summary of primary molt in adult Common Ground Doves by month. 
Table 4. Summary of primary molt in adult Common Ground Doves by month.

\begin{tabular}{cccccc} 
Month & $\begin{array}{c}\text { \# ads } \\
\text { sampled }\end{array}$ & $\begin{array}{c}\text { \# replacing } \\
\text { Ps }\end{array}$ & $\begin{array}{c}\text { replacing } \\
\text { Ps }\end{array}$ & $\begin{array}{c}\text { \# replacing } \\
\text { Ps in 2 } \\
\text { waves }\end{array}$ & $\begin{array}{c}\text { \# with 2 } \\
\text { active or } \\
\text { inferred } \\
\text { waves }\end{array}$ \\
\hline May & 5 & 1 & 20 & 0 & 4 \\
Jun & 5 & 3 & 60 & 1 & 3 of $3^{1}$ \\
Jul & 54 & 48 & 89 & 10 & 6 of $50^{1}$ \\
Aug & 19 & 11 & 58 & 2 & 3 of $15^{1}$ \\
Sep & 49 & 39 & 80 & 5 & 12 of $48^{1}$ \\
\hline Totals & 132 & 102 & 77 & 18 & 31
\end{tabular}

${ }^{1}$ Primaries were not assigned ages in some birds, precluding inferring additional waves. 


\section{Table 5 (on next page)}

Summary table for 108 adult Common Ground Doves that were growing primaries. 
Table 5. Summary table for 108 adult Common Ground Doves that were growing primaries.

\begin{tabular}{|c|c|c|c|c|c|c|c|c|c|c|c|c|c|c|c|c|c|c|c|}
\hline & $\mathrm{P} 1$ & & $\mathrm{P} 2$ & & P3 & & $\mathrm{P} 4$ & & P5 & & P6 & & P7 & & P8 & & P9 & & $\begin{array}{c}\text { P1 } \\
0 \\
\end{array}$ \\
\hline \# nodal & 12 & & 0 & & 0 & & 0 & & 0 & & 2 & & 3 & & 0 & & 2 & & 1 \\
\hline \# distal & & 6 & & 8 & & 16 & & 29 & & 29 & & 40 & & 38 & & 26 & & 12 & \\
\hline \# proximal & & $4^{1}$ & & 0 & & 0 & & 0 & & 0 & & 0 & & 0 & & 0 & & 6 & \\
\hline \# terminal & 0 & & 0 & & 0 & & 0 & & 0 & & 0 & & 3 & & 1 & & 1 & & 9 \\
\hline \# growing & 8 & & 4 & & 8 & & 15 & & 19 & & 21 & & 25 & & 19 & & 12 & & 11 \\
\hline
\end{tabular}

${ }^{1}$ These 4 exceptions to distal replacement are likely unavoidable scoring problems caused by P1 being a pin or short feather. P1 was presumable initiating a new wave in each case, but was too short to be compared with its neighboring inner primaries, which were little worn. 


\section{Table 6 (on next page)}

Association between primary replacement and active crop glands in adults. 
Table 6. Association between primary replacement and active crop glands in adults.

Not

Molting Ps molting Ps \% molting

Crop gland active

8

6

57

Crop gland not active

30

1

97 


\section{Table 7 (on next page)}

Mean primary lengths (standard deviations in parentheses) and growth rates for Common Ground Doves.

Primary growth rates were measured from growth bands in 2 or 3 feathers; standard deviations are given when there were 3 measurements. 
Table 7. Mean primary lengths (standard deviations in parentheses) and growth rates for Common Ground Doves. Primary growth rates were measured from growth bands in 2 or 3 feathers; standard deviations are given when there were 3 measurements.

\begin{tabular}{lccc} 
& \multicolumn{2}{c}{ Primary length } & $\begin{array}{c}\text { Primary growth } \\
\text { rate }(\mathrm{mm} / \mathrm{d}) \\
\text { (Sexes combined) }\end{array}$ \\
\cline { 2 - 3 } P1 & $51.8(0.75)$ & $54.1(1.69)$ & 2.88 \\
P2 & $52.9(1.10)$ & $54.8(1.47)$ & 2.72 \\
P3 & $53.7(0.76)$ & $55.5(1.38)$ & $2.68(0.63)$ \\
P4 & $55.1(1.28)$ & $56.9(0.67)$ & $2.90(0.18)$ \\
P5 & $56.9(1.02)$ & $59.1(0.92)$ & 2.78 \\
P6 & $61.0(1.29)$ & $63.0(1.27)$ & 2.44 \\
P7 & $63.5(0.58)$ & $64.7(1.48)$ & 3.61 \\
P8 & $63.6(0.89)$ & $65.2(1.17)$ & 3.03 \\
P9 & $62.5(0.84)$ & $63.8(0.75)$ & $3.15(0.38)$ \\
P10 & $59.4(0.67)$ & $60.3(0.82)$ & $3.01(0.29)$
\end{tabular}

